\title{
Common Digital Space Scientific Knowledge Designing: Theoretical and Methodological Problems
}

\author{
Natalie Lopatina ${ }^{1[0000-0001-8135-0384]}$, Irina Sobolevskaya 2 [0000-0002-9461-3750] \\ ${ }^{1}$ Federal Institute of Industrial Property, Russia, Moscow, Beregskovskaya nab., 30 \\ ${ }^{2}$ Joint Supercomputer Center of Russian Academy of Sciences - Branch of Federal State \\ Institution "Scientific Research Institute for System Analysis" of Russian Academy \\ of Sciences, Leninskiy pr., 32a, 119334, Moscow, Russia \\ ${ }^{1}$ dreitser@yandex.ru, ${ }^{2}$ insejscc.ru
}

\begin{abstract}
Unsolved methodological problems of creating a single digital knowledge space are considered. The methodology of information space intellectualization is presented as one of the priority trends of modern information development. The characteristics of the information infrastructure of the digital economy are defined: intellectual type of scientific knowledge storage, visibility. Actual theoretical problems that require operational solutions in the context of designing a single digital space of scientific knowledge are formulated. Solutions to the problems of selecting objects of information modeling and reflection, dialectics of individual and system objects in the structure of a single digital space of scientific knowledge, industry-specific and differentiated approaches to the design of a single digital space of scientific knowledge are proposed. Organizational models of the unified digital space of scientific knowledge are considered. The idea of a single digital space of scientific knowledge is considered through the prism of the experience of organizing inter-organizational projects in the Russian information market.
\end{abstract}

Keywords ${ }^{1}$ : digitalization, unified knowledge space, science, scientific information, scientific and informational activity, information support of Introduction

The high attention to designing of a Common Digital Space of Scientific Knowledge (CDSSK) in the professional press [1, 2, etc.] identifies a range of theoretical and methodological problems of essential importance in this large-scale idea implementation.

The digital space intellectualization is one of the priority trends of modern information development. At the same time, the information flows intellectualization, the phenomena's intelligent virtual representation, predicted in the early 2000-s, have not implemented in the modern information environment. According to Russia's computer

1 CDSSK-2020: International Conference "Common Digital Space of Scientific Knowledge", November 10-12, 2020, Moscow, Russia

EMAIL: dreitser@yandex.ru (Natalie V. Lopatina); ins@ jscc.ru (Irina N. Sobolevskaya)

ORCID: 0000-0003-0367-5575 (Natalie V. Lopatina);

0000-0003-5269-0988 (Irina N. Sobolevskaya)

(c) (i) (c) 2021 Copyright for this paper by its authors. Use permitted under Creative Commons

License Attribution 4.0 International (CC BY 4.0)

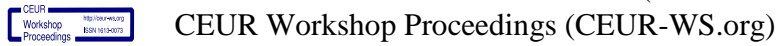


scientist N.A. Slyadneva, "the goal of the intellectualization of the information infrastructure is to create a system of production and transmission of meaningful information to the inputs of the control blocks of society that best meets the task of forming and making managerial decisions" [3]. The digital economy needs a new infrastructure based on an intelligent type of the scientific knowledge storage. It allows to make the scientific achievements of the past and present visible. This visibility is a condition for the rational use of the intellectual resource.

The actual theoretical problems in the CDSSK design include:

- the traditional and digital info space correlation;

- the digital space "quarks" identification (in our opinion, an information system);

- the integration's ideology developing (in our opinion, the meta - information or resource one).

Among the key questions:

1) will the CDSSK be based on the principle of global coverage? Or is it necessary to select data, ideas, documents?

2) If the task of selection is set, what will be its grounds: consumer orientation (information marketing as a response to typical and promising requests, for example) or value selection (in this case: what criteria should select? what is considered socially significant?).

Let's consider several significant issues of the CDSSK designing importance.

1. The information modeling and reflection's object. The design of the CDSSK requires identification of the knowledge representation unit for the information systems. The document-centric paradigm in the info space organization focused analytical and synthetic processing on modeling and reflecting only one information object - a document (despite the availability of IT solutions in extracting "meaning-intensive" text fragments). Modern metadata systems model and reflect the document level (bibliographic models), but not the level of meanings (ideographic models [4]). But the modern researcher lives in the high dynamics and social activity conditions, which deprives him of time not only for studying monographs, articles, abstracts, but also to write and design publications. A new type of professional communication is being laid. It reduces the level of scientific texts. We need in special ways of scientific information presenting, in scientific networks, where a product - the result of intellectual activity - appears.

The CDSSK designing requires archiving and meta-information reflection of the diversity of sovereign information objects: meaning, text, document, author [4], context $[5,6]$, discrete and system objects of different levels [5], processes that ensure the production of new knowledge and its promotion in science and practice.

The CDSSK new contours are outlined by streaming information objects. and their increasing importance in scientific communications (which was confirmed by 2020). The digital heritage preserving cannot be implemented without archiving information messages introduced into public circulation through social networks, the blogosphere, sharing platforms (for example, YouTube). But these innovations require the scientific comprehension. 
2. The dialectical unity of discrete and system objects in the structure of the CDSSK. The methodological foundations of the CDSSK determine the expediency of reflecting not only specific ideas, results of intellectual activity, scientific works, scientists and research teams, but also the continuum of scientific knowledge, its individual subsets and fragments.

The discrete models, reflecting the uniqueness of meanings, ideas, developments, traditionally show their places both in the whole info space also in it subsets (branch, time periods, etc.). A system model consists of a specially organized sum of the discrete models, being, however, non-additive to this sum. This model represents a complete picture of the scientific world (system of sciences).

A process of a system subsets' info reduction creates the basis for its complex analysis, revealing the integrity mechanisms, thanking to which science does not crumble into discrete ideas, texts, topics, but preserves conceptual, meaningful unity. One of the key functions of the system models is to demonstrate the development of ideas, the nature of their social diffusion, their reflection in the info flows and their social evaluation dynamics.

There is a determination of criteria and principles for the formation of system models of scientific knowledge among require theoretical development issues. It's very important to determinate the approaches to its visual representation (mapping, landscape construction, etc.).

3. The expediency of the branch approach in CDSSK designing. It requires taking into account the peculiarities of the formation of branch knowledge, modeling branch information processes, the typological and species diversity specification of the branch information resources. The multidimensional information needs differentiation is the most important task. In this case, we are talking not only about the access to specific information arrays that are important for individual groups of consumers and fields of activity (for example, variable full texts, official documents in the social sciences and humanities, source codes in the information sciences, etc.), but also about the levels and degree of intellectualization of information reducing.

The "accuracy" of knowledge in the technical and natural sciences, the possibility of using an artificial language of mathematical and chemical formulas for its transmission, cliched models of the organization of knowledge arrays that are not applicable in the social and humanitarian sciences. Multiparadigmality, the inevitable dependence of the forms of representation of humanitarian knowledge in any information systems and arrays on ideological attitudes; the complexity of assessing social effectiveness (for example, delayed influence on ideological and ideological platforms, philosophy, a train of interpretations); interpretative diversity; depersonalization, socialization of ideas during the transfer of humanitarian knowledge; a high level of contextuality of connections between fragments of scientific knowledge is not a complete list of factors that require a special approach to the CDSSK in humanities.

4. A differentiated approach in the CDSSK designing. The key point of the CDSSK designing is some connections of a consumer and ideology, content, interface, service system, linguistic support of the info system. 
Universality (as a key characteristic of pre-digital formats for the preservation and dissemination of scientific knowledge, as well as analog projects for their reproduction in a digital environment) does not allow us to go beyond the uncontested logic of linear arrangement in the traditional document arrays, which was partially compensated by bibliographic products and services. Modern IT solutions make it possible to create individualized information products and services within the CDSSK framework, however, this requires the development of differentiated "inputs" for different categories of users, modeling the diversity of search trajectories and thesauruses of users, ideologies for determining and segmenting the target audience. For example, a differentiated reflection of the specifics of the information needs of an expert scientist in a particular field of knowledge and a student or a young researcher.

The differentiated approach in the CDSSK designing is due to the heterogeneity of the target consumers' audience for the new social interaction mechanisms are being laid, ensuring the diffusion of theoretical ideas and developments into the modern economy, into production systems and socio-cultural practices and industries. Heuristic theoretical tools in this situation are, for example, the methodology for analyzing the branch information systems developed by N.A. Slyadneva [3], which identifies a consumer groups variety that is stable for each branch and differentiates them depending on the content and structure of information needs, on the models and orientation of information behavior, on the features of interaction with the external information environment; analytical models of interaction between support groups (stakeholders) [7] and others.

5. Choosing / building an organizational model of the CDSSK. It has already become a textbook idea that new information and communication formats change a person, and the constantly changing information environment forms new and preserves traditional canons of thinking and intellectual creativity. The "institute of memory" model (the main emphasis is the preservation and interpretation of documents) gives way to models based on the ideology of accessibility of information diversity. The transformation of scientific communication models determines the change of the digital space organization paradigm - from subject-object to subject-subject, based on the consumer active participation in the processes of creating and updating content. The individualization ("personalization" [8]) of information activity tools, which has reached the level of a mass actor, radically changes the logic of the formation of a single digital knowledge space. "From the independent satisfaction of information needs with the help of available information arrays, representatives of socio-professional groups that form new knowledge in the digital world create not only meanings and texts (an idea and its description/ formula), but also "document" it, independently introduce it into "official" existence and public use, give it a certain legal status" [9].

This requires rethinking a new quality models of interaction between information systems the creator and the consumer. For example, the "science-blockchain" model is a new organizational format based on the idea as a quark, connected by a single methodology.

The CDSSK-idea is based on the various organizational structures resources integration and consolidation, synergetic access to the meta-corporate level. At the same time, the inter-organizational projects experiences, the specifics of production and business 
relations in the information market (primarily, departmental barriers), the peculiarities of the personnel of the modern infospace (the complex structure of professional resources of information activity, the multilevel confrontation of "strong-resource" and "weak-resource" subjects of the industry, the specifics of professional elites) demonstrate the difficulties of reaching consensus when making the whole range of decisions: from the choice of a technological solution, unity in the issues of ideology and architecture of interaction to leadership in the management of financial flows and attracted investments. This requires a technologized, scientifically based solution in line with the declarations and priorities of the digital economy.

\section{References}

1. Antopolsky, A.B., Efremenko, D.V.: On the question of a single electronic space of knowledge. Bulletin of the Russian Academy of Sciences 88(2). P. 163-170 (2018). https://doi.org/10.7868/S086958731802007X

2. Antopolsky, A.B., Kalenov, N.E., Serebryakov, V.A., Sotnikov, A.N.: On the unified digital space of scientific knowledge. Bulletin of the Russian Academy of Sciences 89(7). P. 728 735 (2019). URL: https://journals.eco-vector.com/0869-5873/article/view/15244. https://doi.org/10.31857/S0869-5873897728-735

3. Slyadneva, N.A.: Information and analytical activity: problems and prospects. Fact (6) (2006). URL: http://www.fact.ru/current/ slyadneva.shtml

4. Slyadneva, N.A.: Bibliography in the system of the Universe of human activity: The experience of system-activity analysis. M.: Publishing house of the IPCC, 1993. 226 p.

5. Lopatina, N.V.: Creation of a computer analogue of a recommendation bibliographic manual on fiction (questions of theory and methodology): Autoref. dis. for the degree of candidate of pedagogical sciences in the specialty 05.25.03. Library science and bibliography. Moscow, 1996. $16 \mathrm{p}$.

6. Suminova, T.N.: Personal documentography of cinema art: theoretical and methodological foundations and development trends: abstract of the dissertation for the degree of candidate of pedagogical sciences in the specialty 05.25 .03 . Library science and bibliography. Moscow: MGUK, 1996. 16 p.

7. Neretin, O.P.: Formation of the mechanism of interaction of support groups in the system of strategic management of cultural institutions: Dissertation for the degree of doctor of economics in the specialty 08.00.05. St. Petersburg State Economic University, 2015. 293 p.

8. Arapov, M.V.: Predictable changes in the information environment of society. Scientific and Technical Information. Ser. 2 (1). P. 1-5 (1991).

9. Neretin, O.P., Lopatina, N.V., Zubov, Yu.S.: Digitalization of the sphere of intellectual property: from scientific justification to practical implementation. Scientific and Technical Information. Series 1 (4). P. 18-22 (2019). 